\title{
A high-voltage lithium-ion battery prepared using a Sn-decorated reduced graphene oxide anode and a $\mathrm{LiNi}_{0.5} \mathrm{Mn}_{1.5} \mathrm{O}_{4}$ cathode
}

\author{
Pier Paolo Prosini ${ }^{1,2} \cdot$ Maria Carewska $^{1}$ - Gabriele Tarquini ${ }^{3}$. \\ Fabio Maroni ${ }^{4} \cdot$ Agnese Birrozzi $^{4} \cdot$ Francesco Nobili $^{4}$
}

Received: 28 July 2015 / Revised: 10 September 2015 / Accepted: 7 October 2015

(C) Springer-Verlag Berlin Heidelberg 2015

\begin{abstract}
This paper describes the preparation and characterization of a high-voltage lithium-ion battery based on Sndecorated reduced graphene oxide and $\mathrm{LiNi}_{0.5} \mathrm{Mn}_{1.5} \mathrm{O}_{4}$ as the anode and cathode active materials, respectively. The Sndecorated reduced graphene oxide is prepared using a microwave-assisted hydrothermal synthesis method followed by reduction at high temperature of a mixture of $\left(\mathrm{C}_{6} \mathrm{H}_{5}\right)_{2} \mathrm{SnCl}_{2}$ and graphene oxide. The so-obtained anode material is characterized by thermogravimetric analysis, X-ray diffraction, scanning electron microscopy, and electron diffraction spectroscopy. The $\mathrm{LiNi}_{0.5} \mathrm{Mn}_{1.5} \mathrm{O}_{4}$ is a commercially available product. The two materials are used to prepare composite electrodes, and their electrochemical properties are investigated by galvanostatic charge/discharge cycles at various current densities in lithium cells. The electrodes are then used to assemble a high-voltage lithium-ion cell, and the cell is tested to evaluate its performance as a function of discharge rate and cycle number.
\end{abstract}

Keywords Tin $\cdot$ Reduced graphene oxide $\cdot \mathrm{LiNi}_{0.5} \mathrm{Mn}_{1.5} \mathrm{O}_{4}$. Composite electrodes $\cdot$ Lithium battery

Pier Paolo Prosini

pierpaolo.prosini@enea.it

1 ENEA, Italian National Agency for New Technologies, Energy and Sustainable Economic Development, Casaccia Research Centre, Via Anguillarese 301, Santa Maria di Galeria, 00123 Rome, Italy

2 Drive the Innovation in Energy Storage (DInESto), Via Province, 04012 Cisterna di Latina, Italy

3 Dip. Scienze di Base ed Applicate per l'Ingegneria, University of Roma La Sapienza, Via Scarpa 14, 00161 Rome, Italy

4 School of Science and Technology, Chemistry Division, University of Camerino, Via S. Agostino, 62032 Camerino (MC), Italy

\section{Introduction}

Lithium-ion batteries (LIBs) represent a milestone for the mobile power sources and are currently used for a large number of electrical applications. Nevertheless, the development of electric storage systems with higher performance requires the development of new electrode materials with higher specific capacity and/or higher voltage. At present, the attention is focused on high-voltage layered metal oxides for the cathode $[1,2]$ and high-capacity lithium storage metals and metal alloys for the anode [3]. The research activity on high-voltage cathode materials represents one of the key challenges for developing new advanced batteries with higher specific energies. $\mathrm{LiNi}_{0.5} \mathrm{Mn}_{1.5} \mathrm{O}_{4}$ (LNMO) with a spinel structure is emerging as one of the most promising active materials for the construction of high-energy Li-ion batteries [4-10]. This is mainly due to its high theoretical gravimetrical specific capacity of $146.7 \mathrm{mAh} \mathrm{g}^{-1}$ coupled with a high working voltage (about 4.7 V below the Fermi energy of a lithium metal anode) leading to a theoretical gravimetrical specific energy as high as $650 \mathrm{Wh} \mathrm{kg}^{-1}$ [10]. Due to the reduced nickel content in the material, the use of LNMO is also attractive from an economical point of view [11]. Lithium storage metals and alloys (intermetallics), such as Sn [12], Sb [13], Te [13], Al [14], Si [15], and $\mathrm{SnSb}$ [12], show high theoretical charge densities and impressive specific capacities and could replace the carbonaceous anode materials. Metallic Sn has a high theoretical capacity ( $993 \mathrm{mAh} \mathrm{g}^{-1}$ or $7262 \mathrm{mAh} \mathrm{cm}^{-3}$ for $\mathrm{Li}_{4.4} \mathrm{Sn}$ ) and a good electric conductivity. It also exhibits a moderate operating voltage that is useful to increase the safety of LIBs during rapid charge/discharge processes. These properties encourage the study of $\mathrm{Sn}$ as alternative anode material for highperformance LIBs [16]. Unfortunately, Sn maintains its good electrochemical characteristics for a little number of cycles and this behavior is caused by the disaggregation of the 
electrode; it is possible to observe dramatic volume change (about $300 \%$ ) as a result of lithium-ion insertion/extraction. Sn nanostructures with metal organic framework [17], encapsulation of nanoparticles in carbon matrix [18], construction of hybrid anodes consisting of nanosized Sn and carbon [19], and dilution of the active material in a conductive matrix (e.g. the mixed-conductor matrix concept [20]) are proposed like possible solutions to improve the structural stability of the material and, consequently, the integrity of the Sn electrode. At the base of these strategies is the idea that low-dimension materials can better withstand the huge volume changes and that the conductive matrix can buffer the volume changes and increase the electrical conductivity of the active material, avoiding electric contact loss. Recently, graphite-based materials such as graphene oxide (GO), graphene, and chemically modified graphene oxides have received much attention for energy storage devices $[21,22]$. The disadvantage of GO is the electrical insulation, increasing with the high presence of $\mathrm{C}-\mathrm{O}$ bonds. The chemical reduction and the thermal annealing are commonly used to reduced GO, obtaining the electrically conducting reduced graphene oxide (RGO). RGO represents an excellent substrate to host active nanoparticles because of its intrinsically high conductivity, flexibility, large surface area, and chemical stability [23]. The chemical way to reducing GO involves the use of strong reducing agents, including hydrazine [24], hydroquinone [25], or $\mathrm{NaBH}_{4}$ [26]. Another proposed method requires the use of an acid solution added with metal powders (e.g., Fe and $\mathrm{Al}$ ) [27, 28]. Alternatively, thermal annealing in $\mathrm{H}_{2}$ or mixture of $\mathrm{H}_{2}$ and $\mathrm{Ar}$ is reported to remove effectively the oxygen from the GO $[29,30]$. Several techniques can be found in the literature to prepare $\mathrm{Sn}$-graphene hybrids with various structures such as directly Sn-decorated graphene [31-34], Sn@C nanoparticles [35, 36], Sn@graphene [37-39], and sandwich-like graphenesupported hybrids [38-42]. Despite these hybrids have good electrochemical performances, at high charge/discharge rates, their cyclability is similar to other Sn carbon hybrid anodes. The poor rate performance of these Sn-based electrodes can be ascribed to four main factors: (i) the graphene nanosheets can regroup or stack irreversibly [43], (ii) the synthesis of RGO for exfoliation or reduction can introduce structural defects involving decreasing of stability and electronic conductivity [44], (iii) Sn nanoparticles do not always have the same size and are not equally distributed in the layers of graphene [45], and (iv) the graphene nanosheets not always have successful contact with adjacent Sn nanoparticles [46]. Moreover, the presence of nanostructures exposing active Sn can increase the irreversible capacity due to the direct contact with electrolyte causing possible side reactions at the interface [44]. Microwave-assisted hydrothermal synthesis method is also used for the preparation of $\mathrm{SnO}_{2}$-graphene nanocomposites. Zhong et al. obtain materials with stable capacity [47], while $\mathrm{Zhu}$ et al. achieved $\mathrm{SnO}_{2}$-graphene composites with homogeneous distribution of tin oxide particles (100$200 \mathrm{~nm}$ ) [48]. This preparation technique has many advantages with respect to conventional preparation methods such as fast heating and high efficiency. Microwave-assisted hydrothermal synthesis method is also used to impart novel structures and special morphologies to the active material for both anode and cathode [49, 50]. In this paper, we prepared a $\mathrm{Sn}$-graphene composite to be used as an anode in LIB. The novelty of our approach consists in the preparation of a composite with a homogeneous size distribution of tin particles. This result is obtained using the microwaveassisted hydrothermal synthesis method. The Sn-graphene composite is obtained by heating a metal organic tin compound and $\mathrm{GO}$ in $\mathrm{H}_{2} / \mathrm{Ar}$ atmosphere. The tin particles can reduce the irreversible aggregation of the graphene nanosheets, considered one of the causes of the capacity fade of the electrode. To reduce the problems related to unwanted side reactions between $\mathrm{Sn}$ and the electrolyte and to better control the size and distribution of Sn nanoparticles in the graphene layers, the amount of tin is kept very low. In order to enhance the electrode characteristics of the SnRGO electrode, we used a commercially available acrylic-styrene copolymer (Pattex PL50) as a binder. Pattex PL50 is a waterbased dispersion of polystyrene acrylate (PSA) copolymer. In addition to the PSA copolymer, it contains some fillers and thickeners (mainly calcium carbonate). The PSA copolymer has a high chemical stability due to the absence of residual double bonds and a very high glass transition temperature, and consequently, the polymer film is very rigid. The chemical and physical characteristics that the polymer imparts to the resulting film are very good: high hydrophobicity, low water absorption, and great mechanical strength. In this paper, we present the synthesis and characterization of Sn-decorated RGO. The material is used to prepare an electrode tape using PSA copolymer as the binder, and the electrochemical properties of the electrode are tested at various charge/discharge rates. Finally, high-voltage lithium-ion battery is fabricated, coupling the SnRGO electrode with a LNMO-based cathode, and the electrochemical properties of the cells are studied as a function of current density and cycle number.

\section{Materials and methods}

Preparation of the Sn-decorated RGO The synthesis procedure is detailed elsewhere [51]. Briefly, in a standard preparation, $0.5 \mathrm{~g}$ of GO (NanoInnova Technologies SL, Madrid) is dispersed by sonication in $50 \mathrm{ml}$ of ethylene glycol (EG) until the formation of a stable suspension. $1.50 \mathrm{~g}$ of polyacrylic acid (PAA, MW 2000; Sigma-Aldrich) is dispersed by sonication in about $20 \mathrm{ml}$ of EG. A $0.05 \mathrm{M}$ solution of phenyltin chloride $\left[\left(\mathrm{C}_{6} \mathrm{H}_{5}\right)_{2} \mathrm{SnCl}_{2}\right]$ is prepared, dissolving $0.344 \mathrm{~g}$ of the salt in 
about $20 \mathrm{ml}$ of EG. The dispersion of PAA is added to the dispersion of GO dropwise, and the resulting suspension is allowed to sonicate for $2 \mathrm{~h}$. The solution of phenyltin chloride is slowly added dropwise to the suspension of GO/PAA under vigorous stirring. The resulting mixture is sonicated for $2 \mathrm{~h}$. The reaction mixture is placed in a microwave oven and irradiated with a power of $900 \mathrm{~W}$ for $10 \mathrm{~min}$ under stirring. The formed black solid is separated from the residual solution by filtration, washed three times with ethanol, and dried in air at $50{ }^{\circ} \mathrm{C}$. The residue is processed in an oven at $800{ }^{\circ} \mathrm{C}$ in $\mathrm{Ar} / \mathrm{H}_{2}$ atmosphere (95:5) for $5 \mathrm{~h}$ and left to cool at room temperature.

Preparation of the Sn-decorated RGO anode tape $0.3 \mathrm{~g}$ of Sn-decorated RGO and $0.068 \mathrm{~g}$ of carbon black (Super P; MMM Carbon) are weighed and then transferred to a mill for the mixing. $0.032 \mathrm{~g}$ of Pattex PL50 (Henkel Düsseldorf, Germany) with a solid mass fraction of $90 \%$ is dispersed in $5 \mathrm{~g}$ of water. The suspension is subsequently added to the powder mixture, and the components are mixed by operating the mill for a few minutes. The suspension that is thus obtained is used to paint a copper sheet covering a surface area of $100 \mathrm{~cm}^{2}$. After drying in air at $130-150{ }^{\circ} \mathrm{C}$, the procedure is repeated as many times as it is necessary to use up the entire suspension. A typical negative electrode composition is $75.8 \mathrm{wt} \%$ SnRGO, $7.0 \mathrm{wt} \%$ Pattex PL50, and $17.2 \mathrm{wt} \%$ Super P. Electrodes are shaped to form a disc with a diameter of $12 \mathrm{~mm}$ and an average thickness of $40 \mu$. The electrode weight ranges from 2.0 to $2.5 \mathrm{mg}$, which corresponds to a specific mass loading of $1.76-2.21 \mathrm{mg} \mathrm{cm}^{-2}$. Lighter electrodes (from 0.9 to $1.1 \mathrm{mg}$ with a specific mass loading of $0.68-0.83 \mathrm{mg} \mathrm{cm}^{-2}$ ) are obtained by punching the electrode tape in proximity of the edges. Prior to the electrochemical characterization, the electrodes are dried by heating under vacuum at $110{ }^{\circ} \mathrm{C}$ for $12 \mathrm{~h}$.

Preparation of the LNMO cathode tape A procedure similar to that reported for the preparation of the anode tape is used to assemble the cathode. $0.75 \mathrm{~g}$ of $\mathrm{LiNi}_{0.5} \mathrm{Mn}_{1.5} \mathrm{O}_{4}$ (Nanomyte SP-10; NEI Corporation Somerset, NJ, USA) and $0.10 \mathrm{~g}$ of carbon black (Super P; MMM Carbon, Belgium) are weighed and transferred to a mechanic mill. The powder is mixed by operating the device for a few minutes. A water dispersion of polyvinyl acetate (PVAc) with a solid mass fraction of $50 \%$ is used (Vinavil SpA via Valtellina, 63-20159 Milan, Italy). $0.30 \mathrm{~g}$ of the PVAc dispersion is diluted with $8 \mathrm{~g}$ of water. The suspension of PVAc is added to the powder mixture and mixed by operating the mill for a few minutes. The soobtained suspension is used to paint a thin aluminum sheet covering a surface area of $50 \mathrm{~cm}^{2}$. After drying in air at 130$150{ }^{\circ} \mathrm{C}$, the procedure is repeated as many times as it is necessary to use up the entire suspension. The electrode composition is $75 \mathrm{wt} \% \mathrm{LiNi}_{0.5} \mathrm{Mn}_{1.5} \mathrm{O}_{4}, 15 \mathrm{wt} \%$ PVAc, and $10 \mathrm{wt} \%$ Super P. Electrodes are cut as discs, with a diameter of $12 \mathrm{~mm}$ and a thickness of about $80 \mu$. The electrode weight ranged from 15.6 to $16.0 \mathrm{mg}$, which corresponds to a specific mass loading of $13.8-14.1 \mathrm{mg} \mathrm{cm}^{-2}$. Prior to the electrochemical characterization, the electrodes are dried by heating under vacuum at $110^{\circ} \mathrm{C}$ for $12 \mathrm{~h}$.

Chemical-physical characterization The morphology of the tapes is studied by scanning electron microscopy (SEM). High-magnification microphotographs are taken using an AURIGA, CrossBeam Workstation dual-column focused ion beam-SEM and a JEOL JSM-5510LV. The specimens are directly mounted onto a conductive double face carbon tape, which is previously mounted on a slab. The surface chemistry is mapped with an X-ray energy-dispersive spectroscopy (EDS) system (IXRF EDS-2000). The structure of the material is characterized by X-ray powder diffraction (XRD) analysis (Rigaku Miniflex) using $\mathrm{Cu}-\mathrm{K} \alpha$ radiation. The thermal stabilities are investigated by the simultaneous use of a thermogravimetric (TG) and differential thermal analysis (DTA) instrument (Q600 SDT; TA Instruments) equipped with the Thermal Solution software (version 1.4). The reference for the calibration of temperature is nickel Curie point. Ceramic standard, furnished with instrument, permitted the mass calibration. An aluminum oxide with high grade of purity is used as a comparison material. The experiments are performed with open platinum crucibles (cross section $=0.32 \mathrm{~cm}^{2}$ ) using 10 $12 \mathrm{mg}$ of samples. Starting from room temperature, the sample is heated with a gradient of $10{ }^{\circ} \mathrm{C} \min ^{-1}$ up to $850{ }^{\circ} \mathrm{C}$. The onset temperature is calculated by thermal analysis software (Universal Analysis, version 2.5) as the intersection between the extrapolated baseline and the tangent through the inflection point of the weight vs. temperature curve.

Electrochemical characterization For the electrochemical characterization, circular electrodes with a diameter of $12 \mathrm{~mm}$ are punched from the tape. Their electrochemical features are tested in a two-electrode lithium cell in which lithium acted both as the counter and reference electrode. The cells are set up by sandwiching a glass fiber, used as the separator, between the positive and the negative electrodes. The cycling performance and the cycle life of the cells are evaluated in 2032-type coin cells. A 1.0 M solution of $\mathrm{LiPF}_{6}$ dissolved in EC/DEC (1:1) is used as the electrolyte. The cycling tests are automatically carried out with a battery cycler (Maccor 4000). All experimental activities are performed at $20{ }^{\circ} \mathrm{C}$ in a dry room (R.H. $<0.1 \%$ at $20{ }^{\circ} \mathrm{C}$ ).

\section{Results and discussion}

Chemical-physical characterization of the Sn-decorated RGO The thermal property of the SnRGO and the percentage of tin and carbon in the composite material are determined by 
TG analysis, which is performed in air atmosphere with a heating rate of $10{ }^{\circ} \mathrm{C} \mathrm{min}{ }^{-1}$ from 20 to $850{ }^{\circ} \mathrm{C}$. TGA measurement confirms the reduction of graphene oxide by the thermal treatment. In fact, as shown in Fig. 1, with the increasing of the temperature, the SnRGO shows no weight variations up to $400^{\circ} \mathrm{C}$, confirming a good thermal stability due to the absence of labile oxygen functional groups. A small weight loss occurs between 420 and $550{ }^{\circ} \mathrm{C}$, which suggest the oxidation of graphene present on the surface of the SnRGO composite. After that, an important weight change occurs between 550 and $650{ }^{\circ} \mathrm{C}$, which can reveal the oxidation of graphene present on the bulk of the composite material. The DTA shows a peak centered at $625^{\circ} \mathrm{C}$. With further heating, a little weight loss is observed for temperatures lower than $750{ }^{\circ} \mathrm{C}$

The weight percentage of the final residue is about $8.76 \mathrm{wt} \%$. Considering that at elevated temperatures and in air the tin is completely converted into $\mathrm{SnO}_{2}$, this value corresponds to the tin content in the composite (expressed as $\mathrm{SnO}_{2}$ ). Figure 2 shows the SEM image of the SnRGO composite material. It is possible to observe a fairly compact structure in which graphene layers are stacked and wrapped around each other, resembling a foliated graphite obtained by chemical flaking of natural graphite [52]. The porosity of the material is very high. The presence of spherical particles deposited on the surface of the graphite sheets is also noted. EDS analysis allowed to identify the chemical nature of the particles that results to the formation of tin. The Sn particles have a size ranging from $200 \mathrm{~nm}$ up to $400 \mathrm{~nm}$ and are highly dispersed on the RGO surface. The composite material appears rather uniform in size and shape; however, the particles are not homogeneously distributed on the graphene sheets. From EDS analysis, it is also possible to observe that the tin oxide produced by thermal decomposition of the organic precursor remains uniformly dispersed into the graphene matrix. On the other hand, metal tin tends to agglomerate forming the

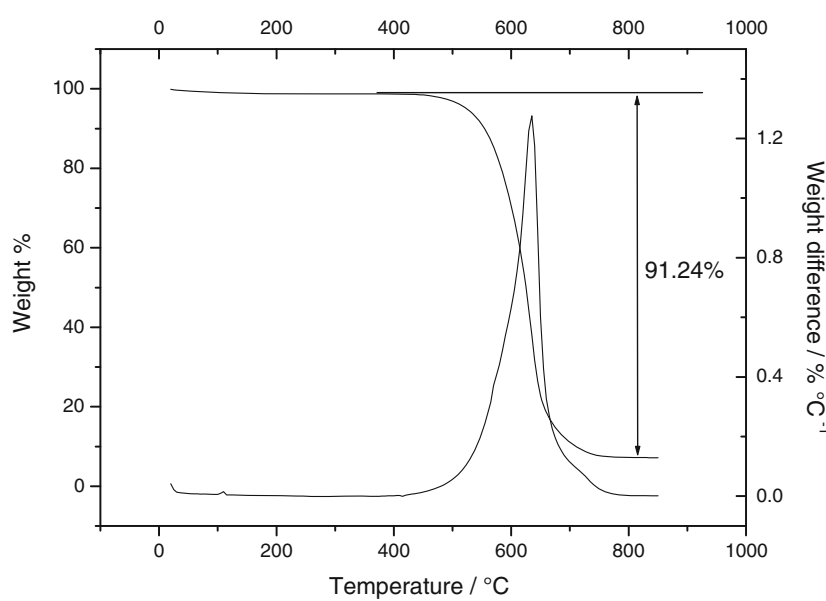

Fig. 1 Thermogravimetric analysis for the SnRGO sample, carried out in air at a heating rate of $10{ }^{\circ} \mathrm{C} \mathrm{min}-1$ spherical particles observed by SEM. This is probably due to the fact that the tin at the operative reduction temperature of $800{ }^{\circ} \mathrm{C}$ is in a liquid form.

XRD analysis (Fig. 3) gives further knowledge on the crystal structure and chemical structure of the tin present in the particles. All the peaks shown in Fig. 3 can be indexed as belonging to crystalline tin and tin oxide with a Cassiterite structure, as reported in the Joint Committee on Powder Diffraction Standards (JCPDS) card nos. 4-673 and 41-1445, respectively. The peak located at $2 \theta=30^{\circ}$ and indicated in Fig. 3 with an asterisk can be related to the presence of $\mathrm{SnO}$ with a Romachite structure (JCPDS card no. 6-395) that has the major reflection peak, corresponding to [010] plane, located at $2 \theta=29.96^{\circ}$. The $\mathrm{SnO}$ can be originated by a partial reduction of $\mathrm{SnO}_{2}$ during the thermal annealing in $\mathrm{H}_{2} / \mathrm{Ar}$ atmosphere. As regards the peak centered at about $2 \theta=26.6^{\circ}$, it typically describes the formation of a RGO structure [53, 54], which tends to partially restack during the hightemperature treatment (graphene nanosheets).

\section{Chemical-physical characterization of the PSA-SnRGO} tape The TGA and the differential thermal gravimetry (DTG) profiles for the decomposition of the PSA-SnRGO tape in air are shown in Fig. 4. There is no mass loss up to $200{ }^{\circ} \mathrm{C}$. By increasing the temperature, the thermal profile shows a behavior that can be related to the PSA depolymerization. This weight loss is related to the decomposition of oligomers with mostly head-to-head linking. A first peak, related to the PSA main-chain decomposition, can be observed in the DTG between 230 and $435{ }^{\circ} \mathrm{C}$ with a maximum centered at $386{ }^{\circ} \mathrm{C}$. The decomposition temperature is comparable to that observed by Reza-Azimi et al. [55] for polystyrene methyl methacrylate. The total weight loss in this temperature range is about $7.43 \mathrm{wt} \%$, higher than the percentage of binder into the electrode. This phenomenon could be imputed to the oxidation of the reactive graphene sheets present on the surface of the SnRGO, as previously observed for pure SnRGO. The main weight loss step occurs at temperatures ranging between 400 and $580{ }^{\circ} \mathrm{C}$ with a maximum centered at $570{ }^{\circ} \mathrm{C}$. This step is assimilated to the oxidative degradation of the RGO. The total weight loss in the step is about $62.6 \mathrm{wt} \%$ (the theoretical weight loss in this step should be about $64 \mathrm{wt} \%$ ). It follows that not all the RGOs are burned in this temperature range. This finding is consistent with that found in the previous TGA for which the RGO is completely burned at temperatures above $700{ }^{\circ} \mathrm{C}$. At the end of this degradation step, for temperatures higher than $580{ }^{\circ} \mathrm{C}$, a third degradation step is observed. This step is shown as a shoulder in the down slope of the DTA curve. It can be related to the oxidative degradation of Super $\mathrm{P}$ carbon and the residual part of RGO. A final degradation step occurs for temperatures higher than $625^{\circ} \mathrm{C}$, and it is correlated to the decomposition of $\mathrm{CaCO}_{3}$ content as a filler into the Pattex 50 and the complete oxidation of the residual Super $\mathrm{P}$ 
Fig. 2 Scanning electron micrograph of the SnRGO sample

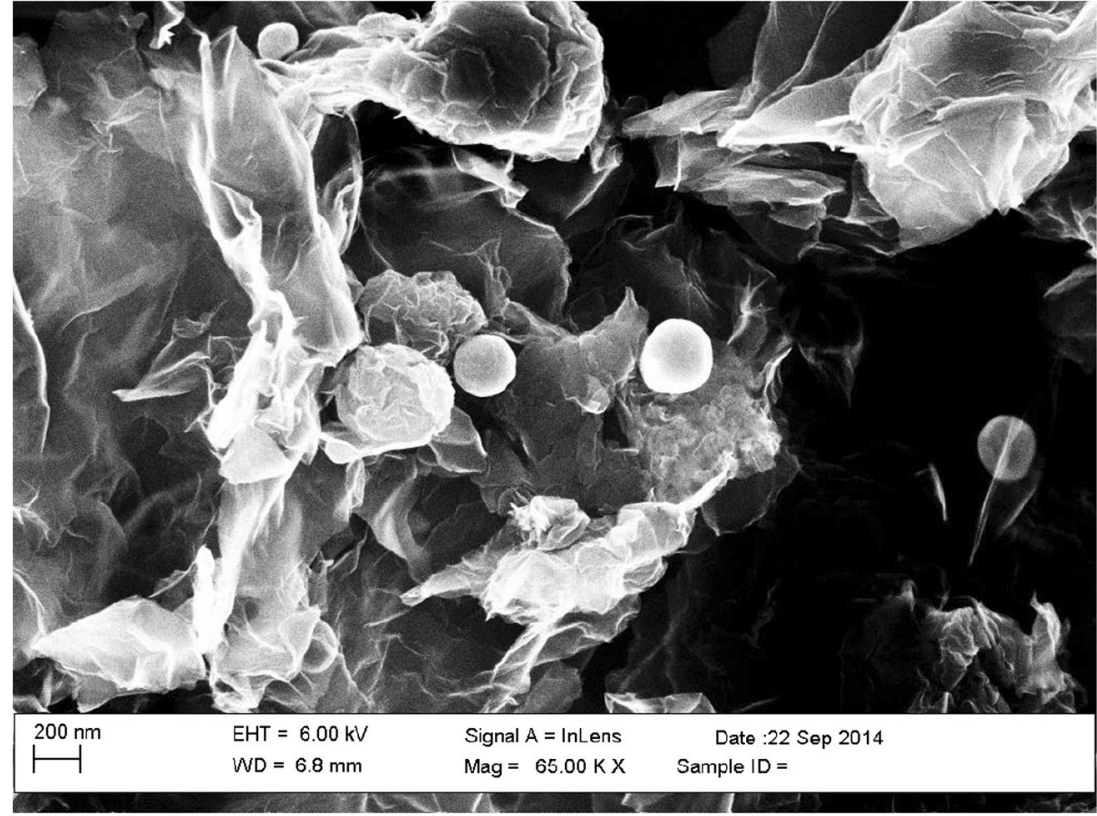

carbon and RGO still present in the sample. The total weight loss extending from $580^{\circ} \mathrm{C}$ up to $690{ }^{\circ} \mathrm{C}$ amounts to $22.4 \mathrm{wt} \%$. The residue of $7.79 \mathrm{wt} \%$ is formed by tin oxide and calcium oxide. Considering the percentage of Pattex 50 into the electrode (about $7.0 \%$ ), the percentage of $\mathrm{CaCO}_{3}$ in the Pattex 50 (about $50 \%$ ), and the percentage of weight loss due to the transformation of $\mathrm{CaCO}_{3}$ into $\mathrm{CaO}(46 \%)$, the theoretical amount of $\mathrm{CaO}$ should be $1.61 \mathrm{wt} \%$. By subtracting the percentage of $\mathrm{CaO}$ from the final residue, it is possible to obtain the percentage of $\mathrm{SnO}_{2}$ which amounts to $6.18 \mathrm{wt} \%$. By dividing this value by the percentage of SnRGO in the composite tape $(75.8 \%)$, it is possible to calculate the percentage of tin (expressed as $\mathrm{SnO}_{2}$ ) into the $\mathrm{SnRGO}$ which amounts to
$8.1 \mathrm{wt} \%$, a value little bit lower than the previously obtained one $(8.76 \mathrm{wt} \%)$.

The thickness and morphology of the electrode tape are investigated by SEM. Figure 5a shows the cross section of the electrode: it appears uniform with a thickness of about $55 \mu \mathrm{m}$. Figure 5b shows the low-magnification image of the anode surface $(\times 100)$. The surface depicted in the figure has an area of about $0.9 \mathrm{~mm}^{2}$. Although the surface is quite smooth, some rough edges emerge from the plane. On the other hand, it is also possible to note the presence of some holes and cracks. The parts that emerge from the surface of the electrode as well as the electrode cracks can be directly related to the deposition process (in which a brush is used for the
Fig. 3 XRD patterns of the SnRGO sample. The diffraction planes for $\mathrm{Sn}$ and $\mathrm{SnO}_{2}$ are reported in black and in gray, respectively

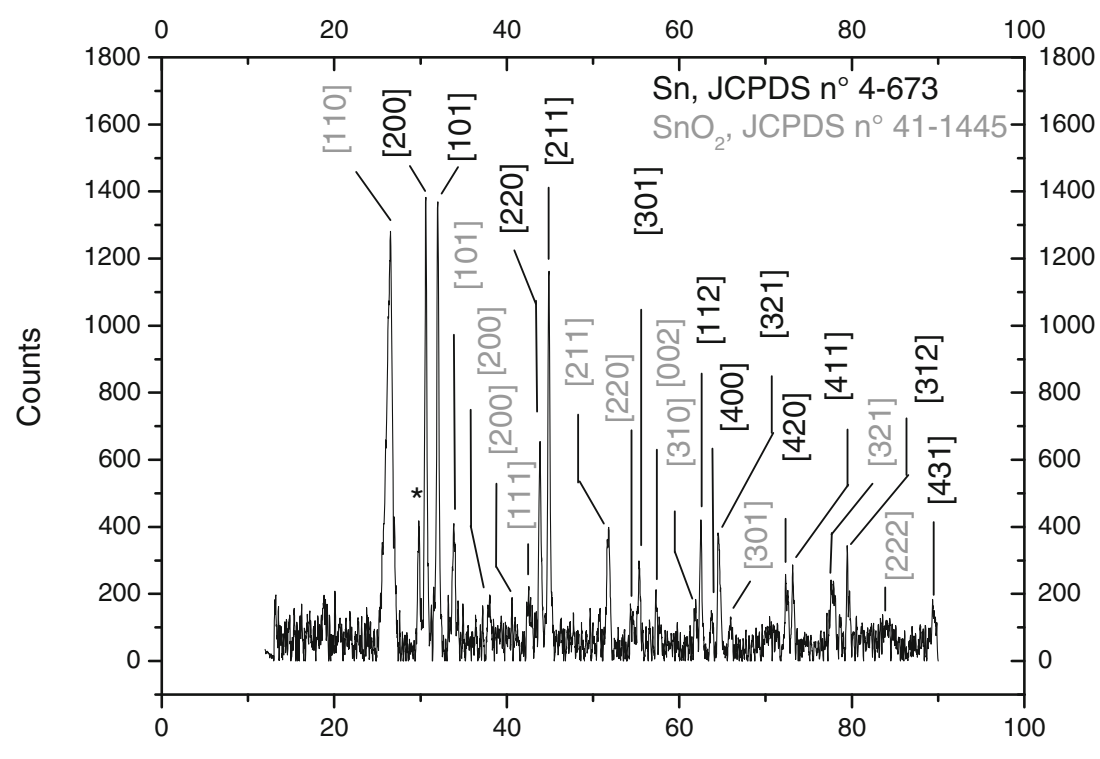

Diffraction angle / 2 theta 
Fig. 4 Thermogravimetric analysis for the PSA-SnRGO electrode tape, carried out in air at a heating rate of $10{ }^{\circ} \mathrm{C} \mathrm{min}{ }^{-1}$

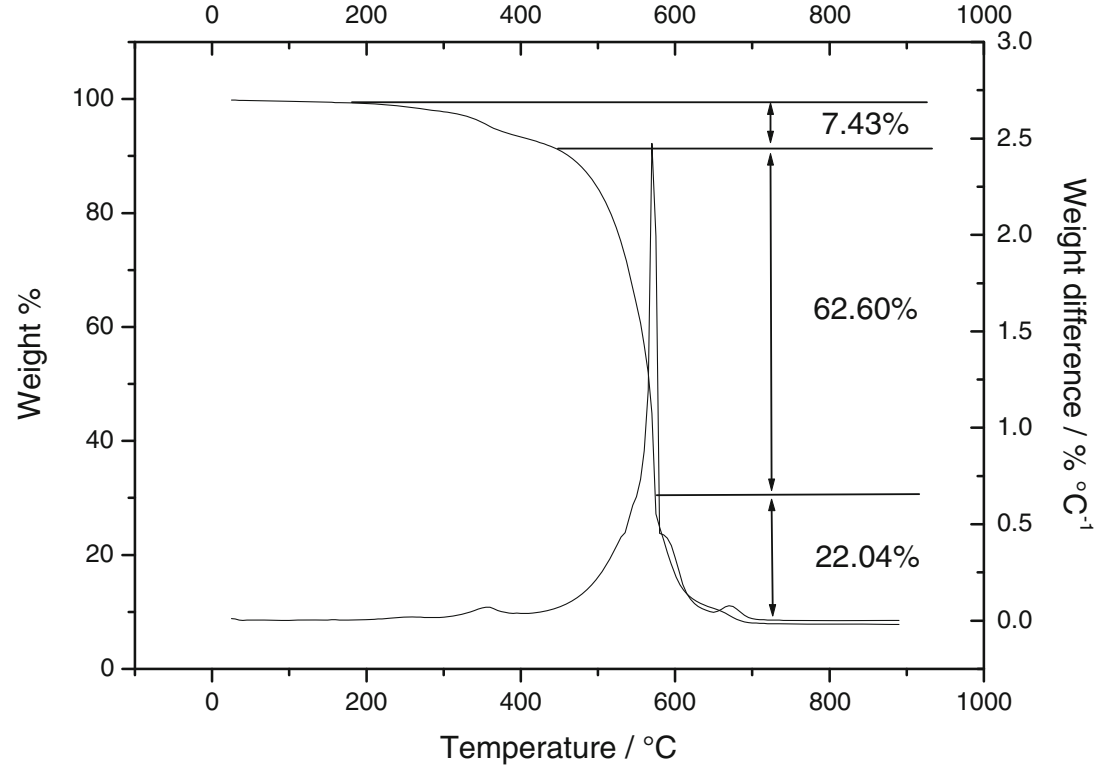

coating of the current collector). The holes are probably formed during the drying phase due to the release of vapor bubbles in which evaporation leaves empty spaces in the tape electrode.

$\mathrm{X}$-ray EDS is performed in order to evaluate the homogeneity and distribution at a microscopic level of the various components within the electrode. The distribution of carbon, oxygen, calcium, and tin is investigated inside the thickness of the electrode. The correspondent distribution maps are depicted in Fig. 6. The carbon appears uniformly distributed on the whole thickness of the electrode. The oxygen content appears very low. This is probably due to the fact that oxygen is present only as $\mathrm{SnO}_{2}$ or $\mathrm{CaCO}_{3}$. Calcium is mapped as a marker to evaluate the uniformity of the binder distribution into the electrode, and it has very good results. Also, the signal of $\mathrm{Sn}$ is equally distributed into the electrode, confirming the uniformity of the electrode and the validity of the covering method to obtain an almost homogeneous electrode.

Electrochemical characterization Figure 7 a shows the first charge/discharge voltage profile for the PSA-SnRGO electrode. The active material in the electrode weighs $1.0 \mathrm{mg}$.
The electrode is cycled at a specific current of $100 \mathrm{~mA} \mathrm{~g}^{-1}$ between 2.0 and $0.01 \mathrm{~V}$. During the first lithiation cycle, the electrode is able to accommodate about $600 \mathrm{mAh} \mathrm{g}^{-1}$. Only part of the capacity accumulated in the first discharge can be extracted from the electrode. In fact, in the following charge, the electrode is able to restore only $380 \mathrm{mAh} \mathrm{g}^{-1}$. The irreversible capacity in the first cycle corresponds to about $37 \%$. As reported by other authors, this irreversible capacity is caused by the degradation of the electrolyte and by the formation of a passivation layer on the electrode surface. Also, the reduction of $\mathrm{SnO}_{2}$ to $\mathrm{Sn}$ contributes to the irreversible capacity [51] being, as demonstrated by XRD analysis, the metal oxide still present in the composite after the thermal treatment under reducing atmosphere. The first-cycle irreversible capacity, and the following reversible charge behavior of the SnRGO electrode, can be better explained by analyzing the differential capacity curve shown in Fig. 7b. The differential capacity $\left(Q_{\text {diff }}\right)$, given by $Q_{\text {diff }}=[d(\mathrm{mAh}) / d(\mathrm{~V})]$, is the derivative of the amount of charge added (charge cycle) or charge removed (discharge cycle) with respect to the cell voltage. The differential profile of the first discharge shows a large amount of capacity exchanged by irreversible processes in the voltage
Fig. 5 Scanning electron micrographs of the PSA-SnRGO electrode tape deposited on a cupper current collector. a High-magnification image $(\times 500)$ of the electrode cross section. $\mathbf{b}$ Low-magnification image $(\times 100)$ of the electrode surface
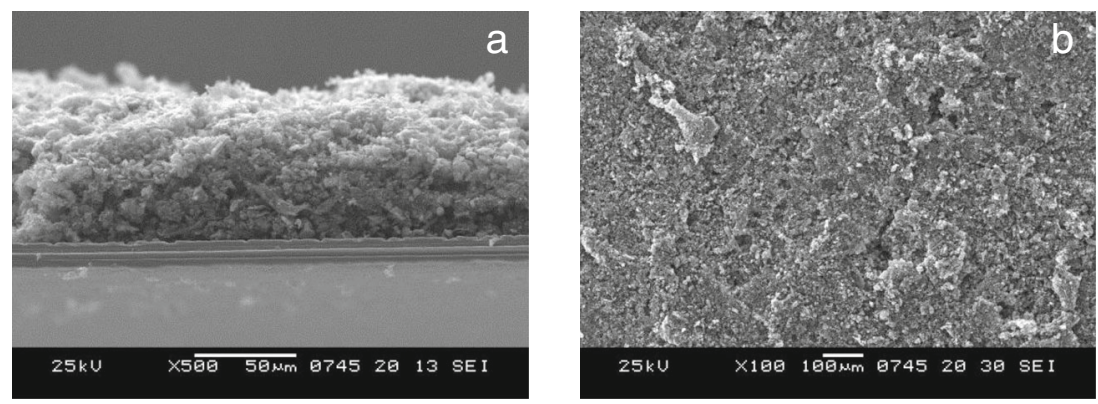
Fig. 6 Distribution maps of the PSA-SnRGO electrode cross section for carbon, oxygen, calcium, and tin as obtained by X-ray energy-dispersive spectroscopy

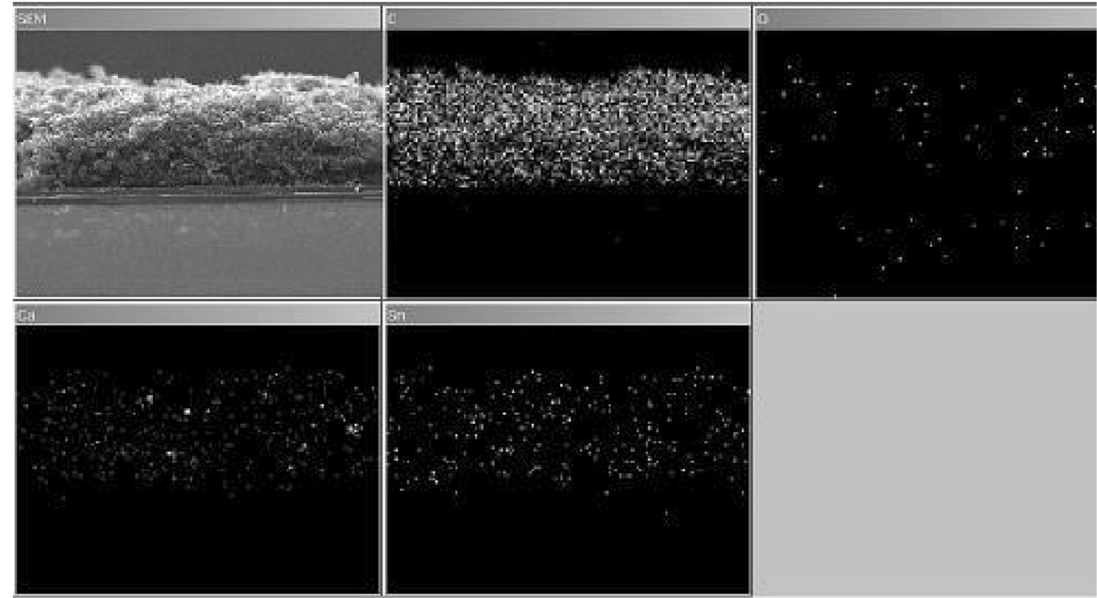

range 0.6 to $0.3 \mathrm{~V}$, with a peak centered at $0.4 \mathrm{~V}(\mathrm{~A})$. This can be mainly ascribed to the formation of a solid electrolyte
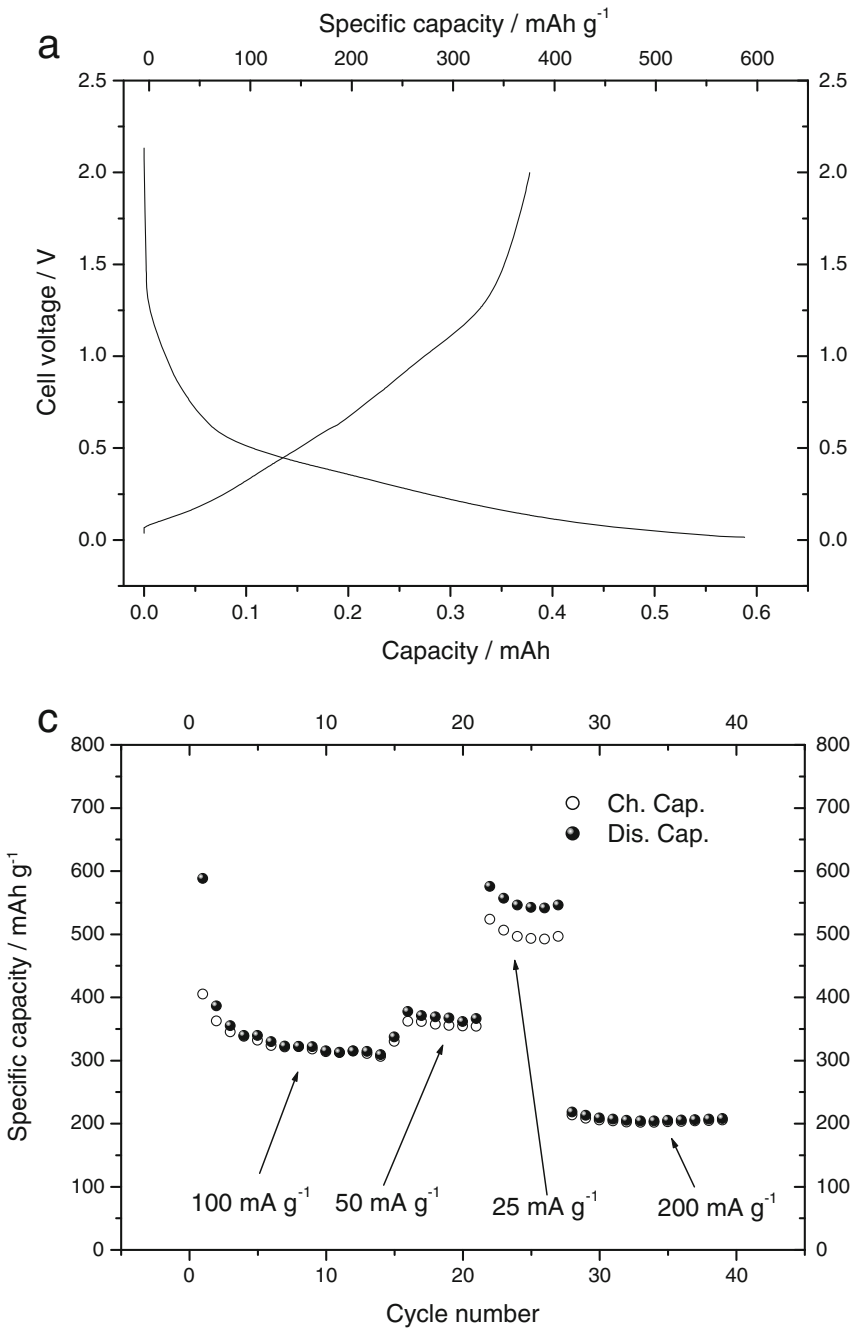

Fig. 7 a First-cycle voltage profile as a function of the capacity for a PSA-SnRGO electrode cycled in a lithium cell at $100 \mathrm{~mA} \mathrm{~g}^{-1}$. b Differential $d Q d E^{-1}$ vs. $E$ curves corresponding to the voltage profiles shown in a. c Specific capacity (in charge and discharge) and Coulombic efficiency interphase (SEI) between the electrolyte and the active material, taking place preferentially at the surface of RGO

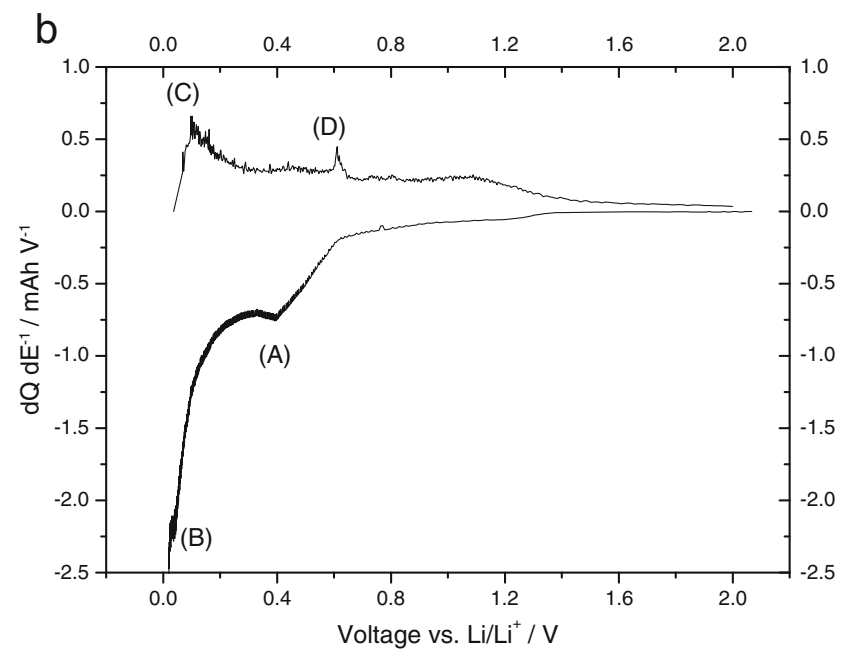

as a function of the number of cycles at various charge/discharge currents. The weight of the electrode active material is $0.98 \mathrm{mg}$. The active material load for unit area is $0.86 \mathrm{mg} \mathrm{cm}^{2}$ 
nanosheets and with the $\mathrm{SnO}_{2}$ reduction. The formation of the SEI is the main reason for the very large irreversible capacity, which is commonly evidenced for composite materials where an amorphous carbon matrix is the main component of the active material $[56,57]$, as in the case for the SnRGO composite under investigation. Further irreversible capacity can be ascribed to Li storage at the surface, cavities, and defects of the disordered carbon $[58,59]$. Below $0.3 \mathrm{~V}$, a high and relatively broad peak shows up (B), corresponding to the sloping plateau in Fig. $7 \mathrm{a}$ at the same potential values. This feature can be associated mainly with $\mathrm{Li}$ intercalation into the partly restacked RGO matrix and, partially, to the Sn lithiation. In the subsequent charge, a couple of peaks are observed: a large one (C) at $0.1 \mathrm{~V}$ followed by a smaller peak (D) centered at $0.6 \mathrm{~V}$. It is noteworthy that $\mathrm{Li}$ extraction still continues to the higher potential and it is completed only at voltages higher than $1.0 \mathrm{~V}$. The first peak (C) can be ascribed to reversible $\mathrm{Li}$ de-intercalation from the RGO, and it accounts for a large part of the reversible capacity. The second peak observed at $0.6 \mathrm{~V}$ and the remaining capacity extracted at voltages between 0.5 and $0.9 \mathrm{~V}$ can be attributed to lithium de-alloying from $\mathrm{Li}_{x} \mathrm{Sn}$ [60].

Figure 7c shows the specific capacity (both in charge and discharge) and the Coulombic efficiency as a function of the number of cycles at various charge/discharge currents. By analyzing Fig. $7 \mathrm{c}$, it is possible to note that the irreversible capacity is not limited to the first cycle but this phenomenon also affects the subsequent cycles. In fact, also if in a reduced manner, the specific capacity in discharge (filled circle in Fig. 7c) is larger than the specific capacity in charge (hollow circle in Fig. 7c). After the 4th cycle, the capacities in charge and discharge assume a similar value and the charge coefficient reaches a unitary value. It is important to highlight that increasing the charge/discharge rate, the irreversible capacity decreases. In fact below $50 \mathrm{~mA} \mathrm{~g}^{-1}$, the difference between the capacity in charge and discharge increases and this effect is boosted when the cycling rate is further decreased down to $25 \mathrm{~mA} \mathrm{~g}^{-1}$. Contrarily, the reversibility of the insertion/deinsertion process is perfectly restored when the cycling rate is increased up to $200 \mathrm{~mA} \mathrm{~g}^{-1}$. This behavior can be explained assuming that the kinetics of the lithium insertion process into the material is larger than that of the parasitic reaction responsible of the irreversible capacity. If this hypothesis is respected, at high charge/discharge rate, the main phenomenon occurring at the electrode is the lithium intercalation in RGO while at low cycling rate, both phenomena can occur, determining a decrease of the efficiency of the process. Figure 8a shows the relation between the capacity (and specific capacity) at the various cycling rates with the voltage trend. At the lowest rate $\left(25 \mathrm{~mA} \mathrm{~g}^{-1}\right)$, a specific capacity approaching $460 \mathrm{mAh} \mathrm{g}^{-1}$ is obtained. By doubling the specific current, the capacity decreases to about $320 \mathrm{mAh} \mathrm{g}^{-1}$. For further doubling of the specific current, the capacity decreases to about $280 \mathrm{mAh} \mathrm{g}^{-1}$. A more remarkable capacity decrease is observed when charging the electrode at $200 \mathrm{~mA} \mathrm{~g}^{-1}$ : the specific capacity goes down to $202 \mathrm{mAh} \mathrm{g}^{-1}$.

To establish the discharge performance of the SnRGO electrode at different current densities, Peukert dependence is measured. The Peukert law is presented by Eq. (1) [61]:

$C_{\mathrm{r}}=T_{\text {dis }} I_{\text {dis }}^{k}$

where $C_{\mathrm{r}}$ represents the rated discharge capacity in $(\mathrm{mAh})$ and $T_{\text {dis }}$ and $I_{\text {dis }}$ are the discharge time and discharge current expressed in hours and milliamperes, respectively. The $k$ parameter is the Peukert constant. The Peukert constant provides an indication of the power capability of the cell: the smaller the value of $k$, the higher the power capability. This parameter is strongly dependent on the battery technology: for lithiumion technology, this parameter changes between 1.00 and 1.28 [62]. The effective capacity $\left(C_{\mathrm{e}}\right)$ is the product of the discharge time and discharge current. By rearranging Eq. (1), we can obtain Eq. (2) in which the effective capacity $\left(C_{\mathrm{e}}\right)$ is related to the rated discharge capacity $\left(C_{\mathrm{r}}\right)$, Peukert constant $(k)$, and discharge current $\left(I_{\mathrm{dis}}\right)$

$C_{\mathrm{e}}=T_{\mathrm{dis}} I_{\mathrm{dis}}=C_{r} I_{\mathrm{dis}}{ }^{1-k}$

To evaluate the Peukert constant $(k)$, the specific discharge capacity is plotted as a function of the specific current in a double logarithmic plot as shown in Fig. 8b. From the slope of the curve, a Peukert constant $(k)$ of 1.37 is calculated.

Once the PSA-SnRGO electrode is electrochemically characterized and before to use the electrode as an anode in a full LIB cell, the electrochemical behavior of the cathode tape is investigated and Fig. 9a shows the discharge voltage trend for the PVAc-LNMO electrode. To quantify the consequence of the lithiation rate on the specific capacity, the electrode is cycled between 4.85 and $3.0 \mathrm{~V}$ at different currents corresponding to the discharge rates of $\mathrm{C} / 10, \mathrm{C} / 5, \mathrm{C}, 2 \mathrm{C}$, and $3 \mathrm{C}$. The charge is performed galvanostatically at $\mathrm{C} / 10$ rate up to $4.85 \mathrm{~V}$. The specific capacity based on the weight of the active material in the electrodes varies with the discharge current. A maximum value of $123 \mathrm{mAh} \mathrm{g}^{-1}$ is obtained by discharging the electrode at $13 \mathrm{~mA} \mathrm{~g}^{-1}$. By increasing the specific discharge current, the specific capacity decreases but the capacity retention is fairly good: the electrode is able to discharge about $93 \%$ of the $\mathrm{C} / 10$ capacity when discharged at specific current 10 times higher and about $86 \%$ of the $\mathrm{C} / 10$ capacity when discharged at currents 30 times higher. The correlation between the electrode performance and the discharge current is better shown in Fig. 9b, reporting in a double logarithmic plot the specific capacity as a function of the specific discharge current. Also, in this case, a linear behavior is observed. The $k$ parameter is evaluated to be 1.037 . The low value of the $k$ parameter is probably related to the nanometric 

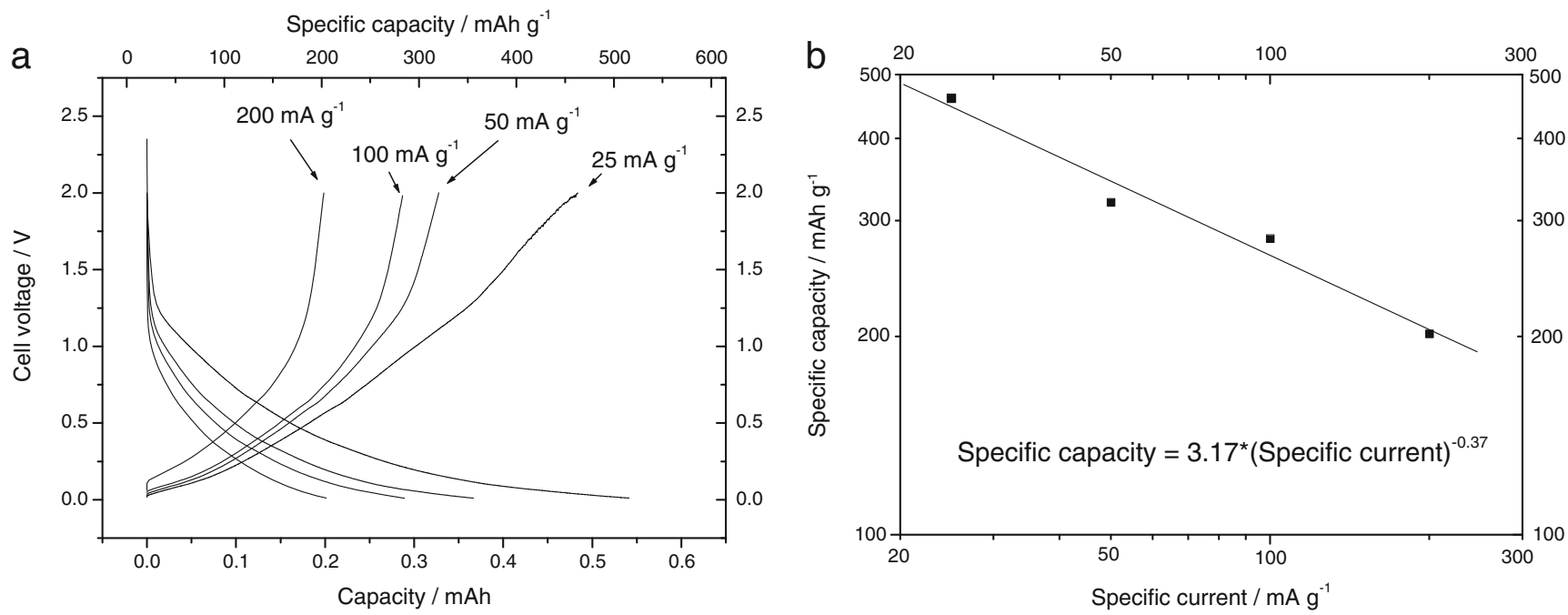

Fig. 8 a Voltage profiles as a function of the capacity for the electrode described in Fig. 7 cycled at various discharge rates. b Double logarithmic plot reporting the specific capacity as a function of the specific current

size of the LNMO that allows to cycle the electrode with good utilization at every discharge rate. Once the electrochemical properties of the positive electrode are evaluated, a full lithium-ion battery cell is built by coupling the PSASnRGO and the PVAc-LNMO electrodes. The characteristics of the positive and negative electrodes used to assemble the lithium-ion battery cell are reported in Table 1 . The battery is perfectly balanced with the ratio between the anode and cathode capacity being equal to 1.0. An initial electrochemical test is carried out by cycling the battery at $0.2 \mathrm{~mA}$. Two end conditions are set in charge regarding the maximum charging capacity $(1.0 \mathrm{mAh})$ and the maximum allowed voltage $(4.95 \mathrm{~V})$. The battery is discharged at the same current down to $2.0 \mathrm{~V}$. Figure 10a shows the charge/discharge voltage profiles for the cell. In the first two charge cycles, the cell is able

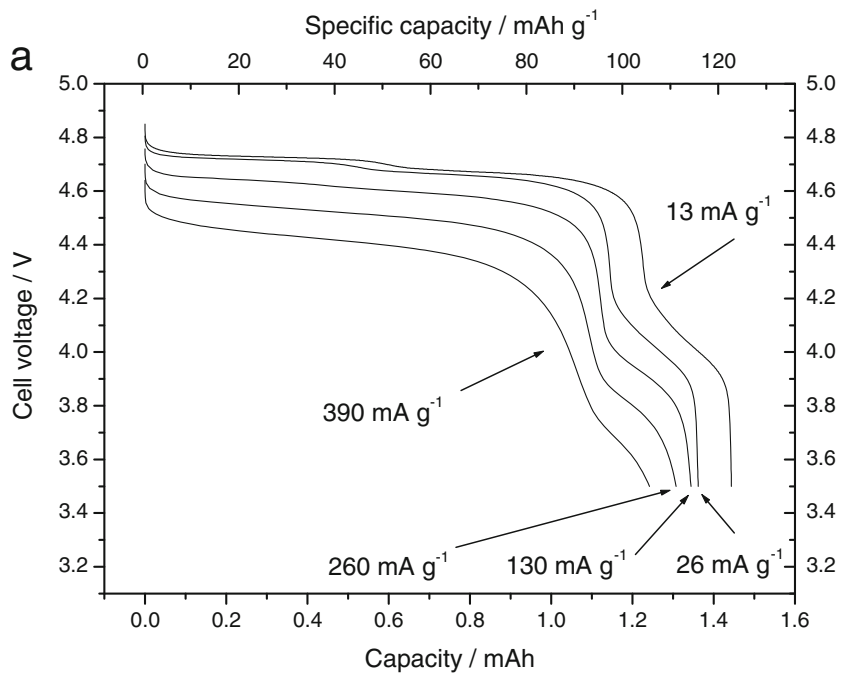

Fig. 9 a Voltage profiles as a function of the capacity for a PVAc-LNMO electrode cycled in a lithium cell at various discharge currents. b Double logarithmic plot reporting the specific capacity as a function of the to charge the maximum amount of allowed capacity (1.0 $\mathrm{mAh})$ without reaching the end voltage condition. Starting from the third cycle, the charge is stopped because the cell reaches the end voltage condition. In the first discharge, only a part of the capacity inserted into the electrode is discharged (about $0.34 \mathrm{mAh}$ ). The irreversible first-cycle capacity is about $66 \%$. The high value of the irreversible capacity is due to the fact that during the first cycle, the cell is not completely charged. After the second cycle, the cell is almost completely charged and the discharge capacity increases to $0.65 \mathrm{~mA}$. The second-cycle discharge capacity is about $76 \%$ of the capacity in charge. During the second cycle, the discharge capacity increased because the irreversible capacity is almost completely consumed during the previous charge cycle. At the third cycle, the cell discharges the

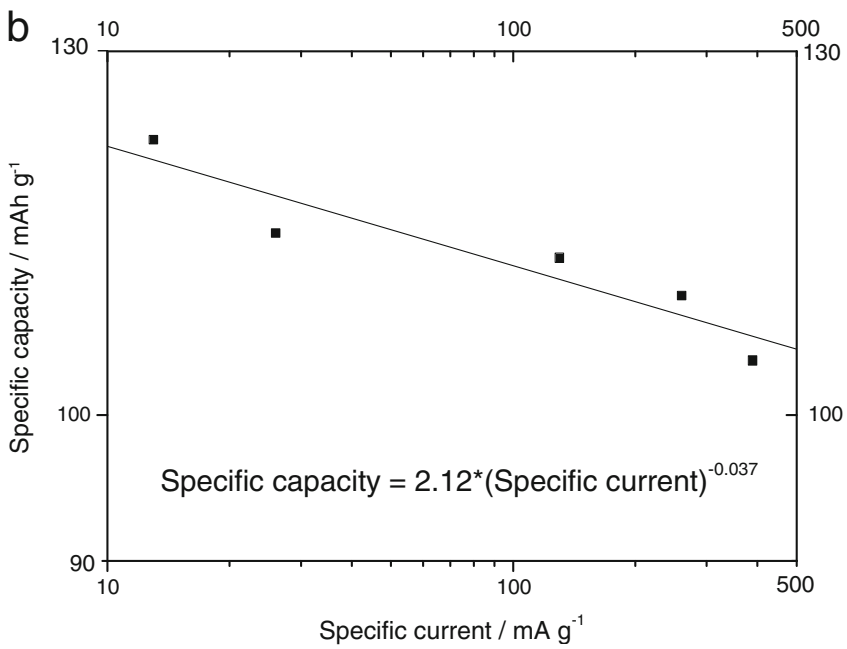

specific current. The weight of the electrode active material is $11.7 \mathrm{mg}$. The active material load for unit area is $10.35 \mathrm{mg} \mathrm{cm}{ }^{2}$ 
Table 1 Characteristics of the positive and negative electrodes used to assemble the lithium-ion battery cell. To calculate the first-cycle capacity, a specific capacity of 588 and $123 \mathrm{mAh} \mathrm{g}^{-1}$ is used for the SnRGO and the LNMO, respectively. To calculate the reversible capacity of the cell, a specific capacity of $300 \mathrm{mAh} \mathrm{g}^{-1}$ is used for the SnRGO electrode

\begin{tabular}{llllll}
\hline Electrode & $\begin{array}{l}\text { Electrode } \\
\text { weight, } \mathrm{mg}\end{array}$ & $\begin{array}{l}\text { Active material } \\
\text { weight, } \mathrm{mg}\end{array}$ & $\begin{array}{l}\text { First-cycle electrode } \\
\text { capacity, mAh }\end{array}$ & Capacity ratio & $\begin{array}{l}\text { Reversible electrode capacity } \\
(\text { at } 100 \mathrm{~mA} \mathrm{~g}), \mathrm{mAh}^{-1}\end{array}$ \\
\hline $\mathrm{C}(+)$ & 16.0 & 12.0 & 1.476 & 1.00 & - \\
$\mathrm{A}(-)$ & 3.3 & 2.5 & 1.470 & 0.99 & 0.75 \\
\hline
\end{tabular}

maximum capacity (about $0.68 \mathrm{mAh}$ ). The discharge processes in the following cycles are all similar to each other as regard the voltage profiles but differ in that the capacity tends to decrease with the progress of the number of cycles. To illustrate the origin of the first-cycle irreversible capacity and the better reversible charge/discharge behavior exhibited at the second cycle, the calculated $d Q d E^{-1}$ vs. $V$ differential profiles for the 2 cycles is shown in Fig. 10b. The differential profile of the first charge shows an amount of capacity exchanged by an
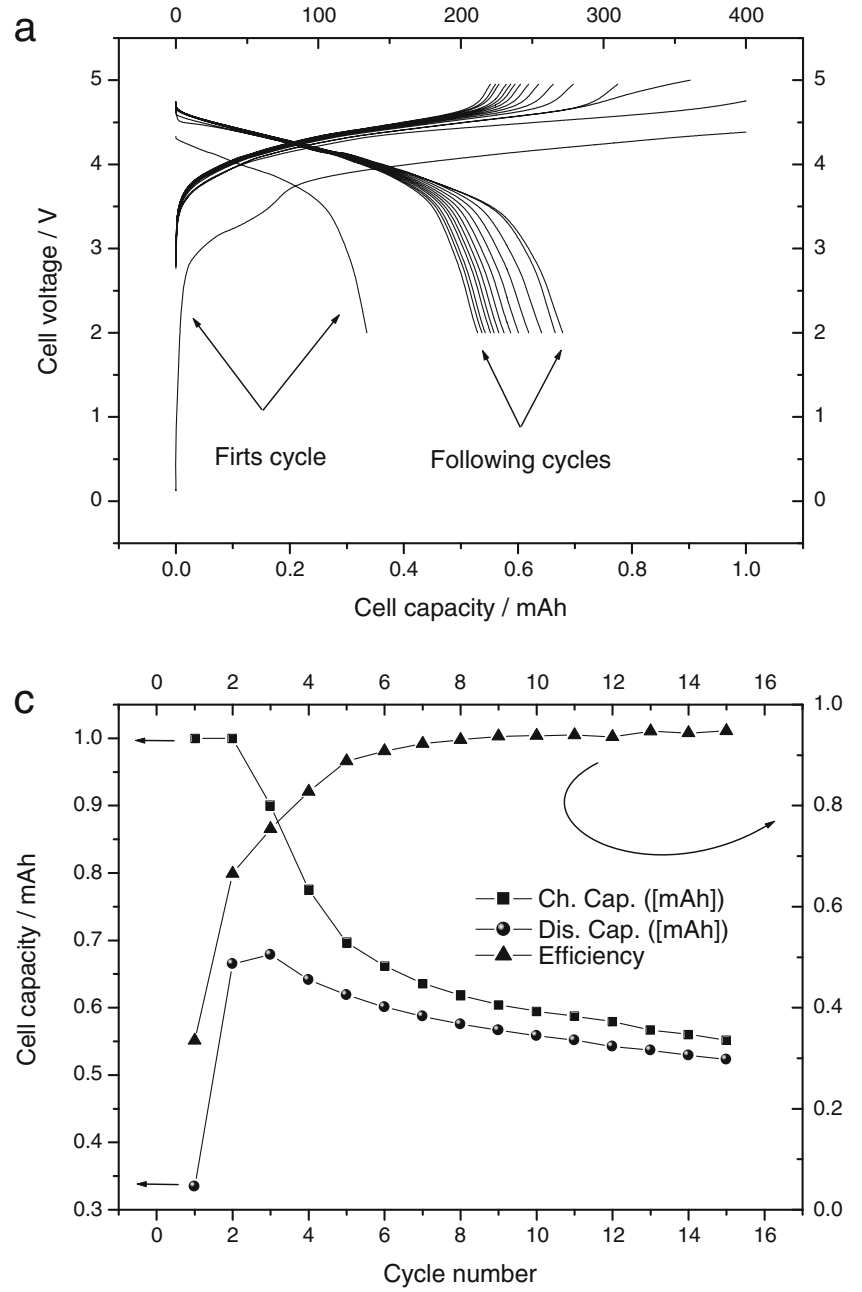

Fig. 10 a Voltage profiles for the first 15 cycles as a function of the capacity for a PVAc-LNMO//PSA-SnRGO Li-ion battery cell cycled at $0.2 \mathrm{~mA}$. b Differential $d Q d E^{-1}$ vs. $E$ curves corresponding to the voltage profiles shown in a. c Capacity (in charge and discharge) and charge irreversible process in the voltage range 2.5 to $3.5 \mathrm{~V}$ (A). A further source of irreversible capacity can be observed between 3.7 and $4.3 \mathrm{~V}$ (B). Process A is completely irreversible because it disappears during the second charge step, while process $\mathrm{B}$ is partially reversible because a part of it is also observed during the second charge step. A third charge process started just after $4.3 \mathrm{~V}$, but it is stopped because the cell reached one of the end charge conditions (the maximum charge capacity is set to $1.0 \mathrm{mAh}$ ). In the first discharge step,

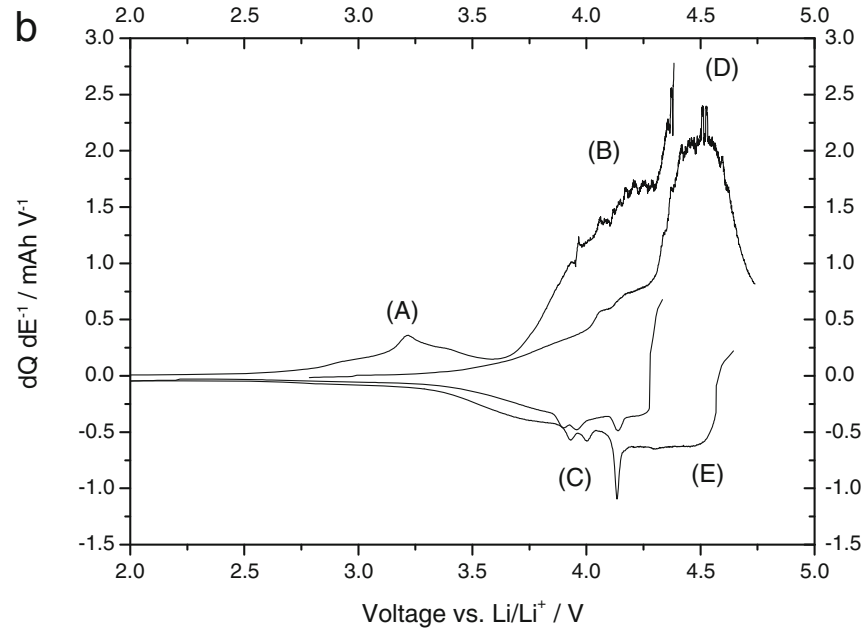

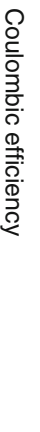

coefficient as a function of the number of cycles. The weights of the electrode active materials for the cathode and the anode are 12.0 and $2.5 \mathrm{mg}$, respectively. The active material loads for unit area for the cathode and the anode are 10.61 and $2.21 \mathrm{mg} \mathrm{cm}^{2}$, respectively 


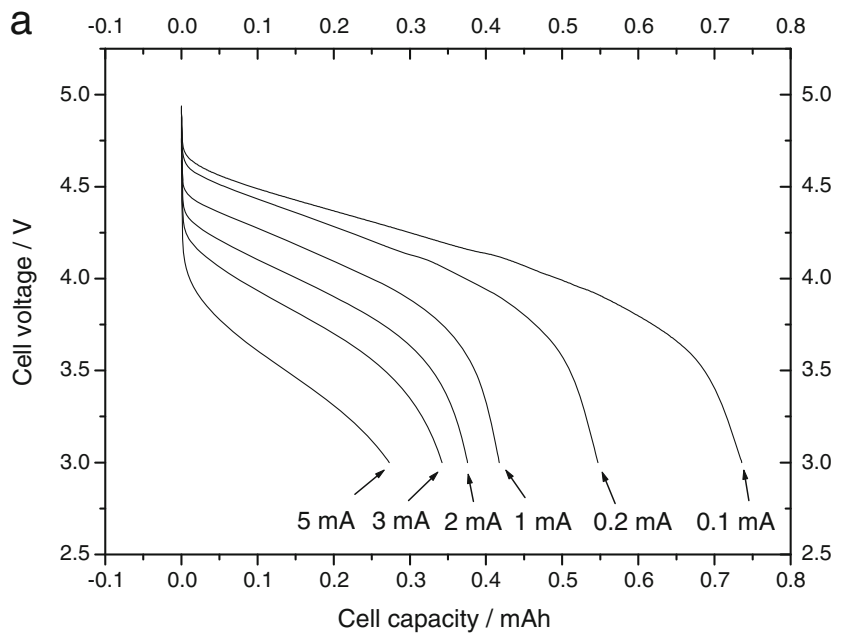

Fig. 11 a Voltage profiles as a function of the capacity for the Li-ion battery cell described in fig. 10 cycled at various discharge currents (the current values are reported in the figure). b Double logarithmic plot

the accumulated capacity is released between 4.3 and $3.3 \mathrm{~V}$ (C). In this voltage range, it is possible to observe three peaks located at 4.14, 3.95, and 3.90 V. These peaks are also observable during the second discharge step although with a small shift with respect to the previous cycle. During the second charge step, process B is strongly reduced in intensity while a large capacity is accumulated between 4.3 and $4.7 \mathrm{~V}$ (D) with a peak centered at $4.5 \mathrm{~V}$. In the second discharge step, a correspondent reduction wave is observed between 4.6 and $4.3 \mathrm{~V}(\mathrm{E})$. The cycle life of the cell can be observed in Fig. 10b where the capacity in charge and discharge is related to the cycle number. In the same figure, the charge coefficient (right axis) is also reported. As previously described, the discharge capacity increases during the first 3 cycles, taking up to $0.68 \mathrm{mAh}$, and then slowly decreases. At the same time also, the charge capacity decreases so that the Coulombic efficiency

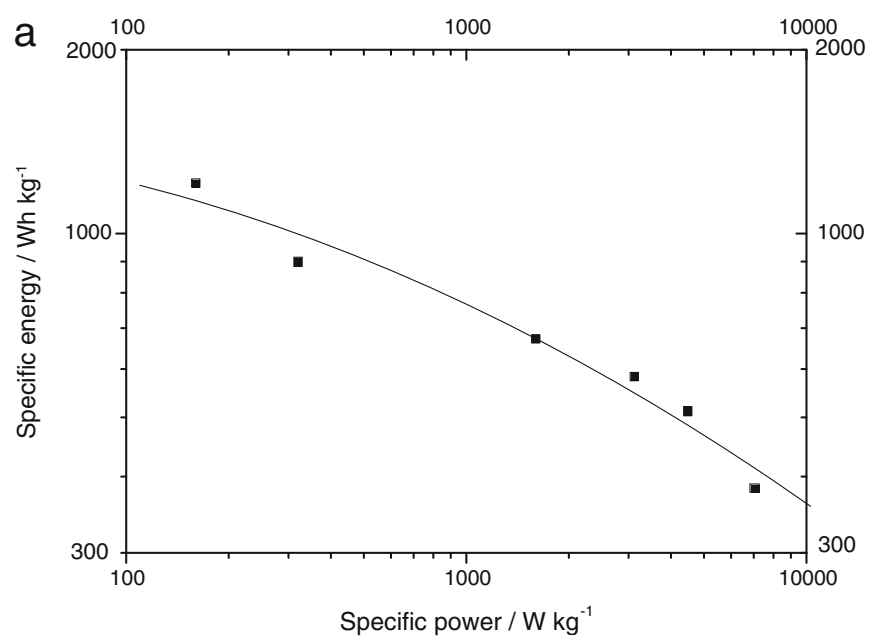

Fig. 12 a Double logarithmic plot of the specific energy as a function of the specific power (Ragone plot). The specific values are referred to the weight of the active material in the anode. b Discharge capacity as a

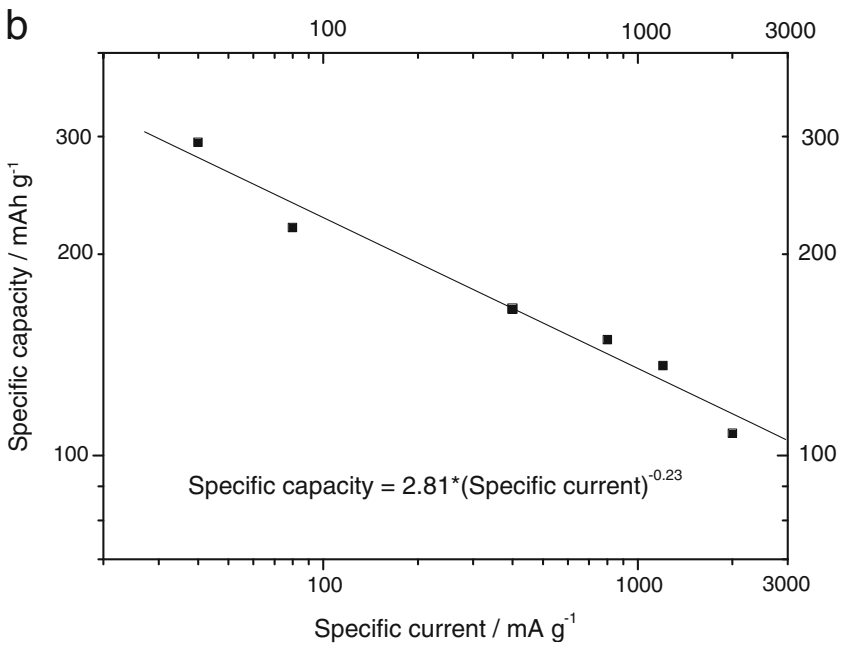

reporting the specific capacity as a function of the specific discharge current

increases with the progress of the number of cycles, rising to 0.95 at the 15 th cycle. At this point, the capacity is reduced down to $0.52 \mathrm{mAh}$. In order to estimate the effect of the discharge rate on the capacity, the cell is cycled at various current densities. The charge is performed galvanostatically at $0.1 \mathrm{~mA}$ up to $4.95 \mathrm{~V}$. Figure 11a shows the voltage behavior of the LIB cell. When discharged at the lower discharge rate $(0.1 \mathrm{~mA})$, the battery is able to provide the theoretical reversible capacity $(0.75 \mathrm{mAh})$. By increasing the discharge current, a decrease in the specific capacity and in the average discharge voltage is observed. The specific capacity decreases to about $0.54 \mathrm{mAh}$ by doubling the current; at $0.41 \mathrm{mAh}$, by increasing the discharge current of 10 times; and at $0.27 \mathrm{mAh}$, by increasing the discharge current of 50 times. The effect of the discharge rate on the performance of the material is summarized in Fig. 11b in which the specific capacity is reported as a function of the

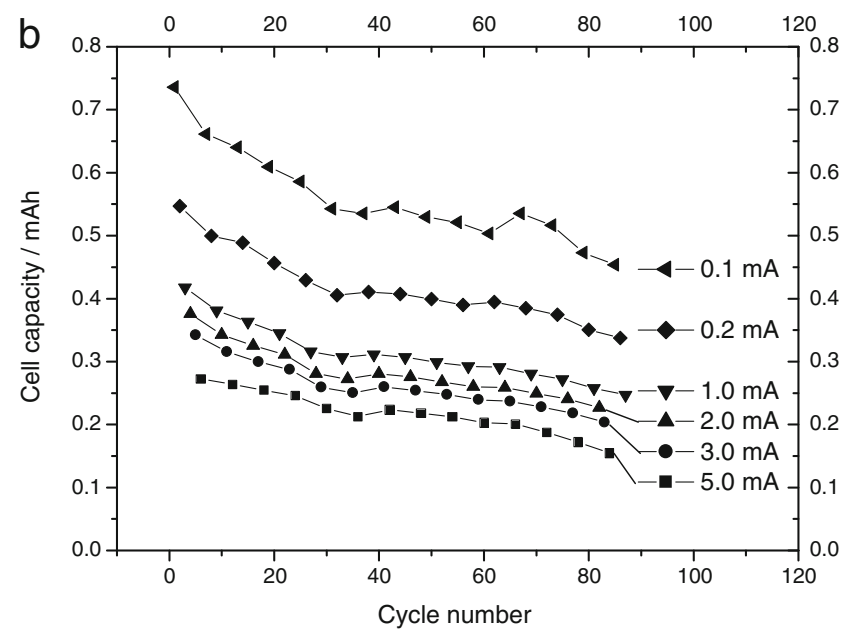

function of the number of cycle number for the Li-ion battery cell described in Fig. 10 cycled at various discharge rates 
specific discharge current in a double logarithmic plot (both the specific values are referred to the weight of the active material in the anode electrode). A linear behavior is observed between the discharge current and the cell capacity: from the slope of the linear interpolation fit, a value of 1.23 is found for the $k$ parameter. This value is slightly lower than the value found for the PSA-SnRGO electrode, and it confirms that the kinetic of the lithium-ion battery cell is anode limited. The effect of the discharge rate on the performance of the material is summarized in the Ragone plot depicted in Fig. 12a in which the specific energy is reported as a function of the specific power in a double logarithmic plot. The specific values are referred to the weight of the active material in the anode. The Ragone plot shows that at low power, the specific energy is about $1210 \mathrm{Wh} \mathrm{kg}^{-1}$ and it is reduced at about $383 \mathrm{Wh} \mathrm{kg}^{-1}$ when the cell is discharged at a specific power in excess of $7000 \mathrm{~W} \mathrm{~kg}^{-1}$. The cyclability of the lithium-ion battery cell is shown in Fig. 12b where the specific capacity is plotted as a function of the cycle number. The capacity fading is pronounced and ranges between 0.5 and $0.55 \%$ per cycle as a function of the discharge rate.

\section{Conclusions}

In this paper, we studied the electrochemical performance of a high-voltage lithium-ion battery cell using Sn-decorated RGO and LNMO as the anode and the cathode, respectively. Microwave-assisted hydrothermal synthesis method allowed to prepare a Sn-decorated GO composite material. As confirmed by XRD analysis and TGA measurement, the GO is almost completely reduced by thermal annealing in $\mathrm{H}_{2} / \mathrm{Ar}$ atmosphere while the $\mathrm{SnO}_{2}$ is only partially reduced. The tin content in the composite expressed as $\mathrm{SnO}_{2}$ is $8.76 \mathrm{wt} \%$. The material presents a compact structure in which graphene layers are stacked and wrapped around each other with spherical tin-based particles deposited on the surface of the graphene sheets. The tin-based particles have a size ranging from $200 \mathrm{~nm}$ up to $400 \mathrm{~nm}$ and are highly dispersed on the RGO surface. An electrode tape with a thickness of about $55 \mathrm{~m}$ is obtained using a commercially available acrylic-styrene copolymer (Pattex PL50). The so-obtained electrode tape shows a good homogeneity between the various chemical elements constituting the electrode. The electrode surface appears rough due to the presence of edges, holes, and cracks. The electrode is found stable up to $200{ }^{\circ} \mathrm{C}$, and it starts to decompose at $230{ }^{\circ} \mathrm{C}$. The electrochemical characterization shows that a large irreversible capacity affects the electrode. This irreversible capacity is related to the degradation of the electrolyte, to the formation of a passivation layer on the electrode surface, and to the reduction of $\mathrm{SnO}_{2}$ to $\mathrm{Sn}$. The irreversible capacity is not limited to the first cycle, but it also affects the subsequent cycles. Furthermore, the irreversible capacity increases by decreasing the charge/discharge rate. This behavior is explained considering the faster kinetics of the lithium insertion into the material with respect to the kinetics of the parasitic reaction responsible of the irreversible capacity. The positive electrode of the lithium-ion battery is prepared using a procedure similar to that reported for the preparation of the anode and using PVAc as the binder. The electrochemical performance of both the electrodes is evaluated at various current densities. The Peukert constant is calculated for both the electrodes to characterize the system response in power. It results that the positive electrode is more performing in power with respect to the negative one. The good response exhibited by the positive electrode is related to the nanometric size of the LNMO used for the preparation of the electrode. The electrochemical performance of the full lithium-ion battery cell built by coupling the PSA-SnRGO and the PVAc-LNMO electrodes is found corresponding to the expectations. In the first lithiation cycle, due to the large first-cycle irreversible capacity, only $34 \%$ of the capacity inserted into the electrode is discharged. The irreversible capacity decreases in the following cycles and the Coulombic efficiency increases rising to 0.95 at the 15 th cycle. When discharged at the lower discharge current, the battery is able to provide its theoretical reversible capacity $(0.75 \mathrm{mAh})$. The specific capacity decreases to about $0.41 \mathrm{mAh}$ by increasing the discharge current of 10 times and at $0.27 \mathrm{mAh}$ by increasing the discharge current of 50 times. A value of 1.23 is found for the Peukert constant. This value is slightly lower than the value found for the PSA-SnRGO anode electrode (1.37), and it confirms that the kinetics of the lithium-ion battery cell is anode limited. The Ragone plot shows that at low power, the specific energy, based on the weight of the active material in the negative electrode, is about $1210 \mathrm{Wh} \mathrm{kg}^{-1}$ and it reduces at about $383 \mathrm{Wh} \mathrm{kg}^{-1}$ when the cell is discharged at a specific power in excess of $7000 \mathrm{~W} \mathrm{~kg}^{-1}$. Relatively high capacity fading affects the cell performance with the progress of the cycle number. The capacity fading ranges between 0.5 and $0.55 \%$ per cycle as a function of the discharge rate.

Acknowledgments Part of this work is carried out within the activities "Ricerca Sistema Elettrico" funded through contributions to research and development by the Italian Ministry of Economic Development.

\section{References}

1. Kim D, Kang S-H, Balasubramanian M, Johnson CS (2010) Highenergy and high-power Li-rich nickel manganese oxide electrode materials. Electrochem Communic 12:1618-1621

2. Kraytsberg A, Ein Eli Y (2012) Higher, stronger, better. A review of 5 volt cathode materials for advanced lithium-ion batteries. Adv Energy Mater 2:922-939

3. Wachtler M, Besenhard JO, Winter M (2001) Tin and tin-based intermetallics as new anode materials for lithium-ion cells. J Power Sources 94:189-193 
4. Zhong Q, Bonakdarpour A, Zhang M, Gao MY, Dahn JR (1997) Synthesis and electrochemistry of $\mathrm{LiNi}_{\mathrm{x}} \mathrm{Mn}_{2-\mathrm{x}} \mathrm{O}_{4}$. J Electrochem Soc 144:205-213

5. Park JS, Roh KC, Lee J-W, Song K, Kim Y-I, Kang Y-M (2013) Structurally stabilized $\mathrm{LiNi}_{0.5} \mathrm{Mn}_{1.5} \mathrm{O}_{4}$ with enhanced electrochemical properties through nitric acid treatment. J Power Sources 230: 138-142

6. Okumura T, Shikano M, Kobayashi HJ (2013) Contribution of oxygen partial density of state on lithium intercalation/deintercalation process in $\mathrm{Li}_{\mathrm{x}} \mathrm{Ni}_{0.5} \mathrm{Mn}_{1.5} \mathrm{O}_{4}$ spinel oxides. $\mathrm{J}$ Power Sources 244:544-547

7. Bhaskar NA, Dixon D, Yavuz M, Nikolowski K, Lu L, Eichel R-A, Ehrenberg H (2014) Improving the rate capability of high voltage lithium-ion battery cathode material $\mathrm{LiNi}_{0.5} \mathrm{Mn}_{1.5} \mathrm{O}_{4}$ by ruthenium doping. J Power Sources 267:533-541

8. Liu D, Trottier J, Charest P, Frechette J, Guerfi A, Mauger A, Julien CM, Zaghib K (2012) Effect of nano $\mathrm{LiFePO}_{4}$ coating on $\mathrm{LiMn}_{1.5} \mathrm{Ni}_{0.5} \mathrm{O}_{4} 5 \mathrm{~V}$ cathode for lithium ion batteries. J Power Sources 204:127-132

9. Zhu Z, Yan H, Zhang D, Li W, Lu Q (2013) Preparation of 4.7 V cathode material $\mathrm{LiNi}_{0.5} \mathrm{Mn}_{1.5} \mathrm{O}_{4}$ by an oxalic acid-pretreated solidstate method for lithium-ion secondary battery. J Power Sources 224:13-19

10. Liu D, Zhu W, Trottier J, Gagnon C, Barray F, Guerfi A, Mauger A, Groult H, Julien CM, Goodenough JB, Zaghib K (2014) Spinel materials for high-voltage cathodes in Li-ion batteries. RSC Adv 4:154-167

11. Kim JH, Pieczonka NPW, Yang L (2014) Challenges and approaches for high-voltage spinel lithium-ion batteries. Chem Phys Chem 15:1940-1954

12. Yang J, Wachtler M, Winter M, Besenhard JO (1999) Submicrocrystalline $\mathrm{Sn}$ and $\mathrm{Sn}-\mathrm{SnSb}$ powders as lithium storage materials for lithium-ion batteries. Electrochem Solid-State Lett 2:161163

13. Zhao XB, Cao GS, Lv CP, Zhang LJ, Hu SH, Zhu TJ, Zhou BC (2001) Electrochemical properties of some $\mathrm{Sb}$ or Te based alloys for candidate anode materials of lithium-ion batteries. J Alloys Comp 315:265-269

14. Hamon Y, Brousse T, Jousse F, Topart P, Buvat P, Schleich DM (2001) Aluminum negative electrode in lithium ion batteries. J Power Sources 97-98:185-187

15. Weydanz WJ, Wohlfahrt-Mehrens M, Huggins RA (1999) A room temperature study of the binary lithium-silicon and the ternary lithium-chromium-silicon system for use in rechargeable lithium batteries. J Power Sources 81-82:237-242

16. Wang B, Luo B, Li XL, Zhi LJ (2012) The dimensionality of Sn anodes in Li-ion batteries. Mater Today 15:544-552

17. Shiva K, Jayaramulu K, Rajendra HB, Maji TK, Bhattacharyya AJ (2014) In-situ stabilization of tin nanoparticles in porous carbon matrix derived from metal organic framework: high capacity and high rate capability anodes for lithium-ion batteries. Z Anorg Allg Chem 640:1115-1118

18. Fan XL, Shao J, Xiao XZ, Wang XH, Li SQ, Ge HW, Chen LX, Wang CS (2014) In situ synthesis of $\mathrm{SnO}_{2}$ nanoparticles encapsulated in micro/mesoporous carbon foam as a high-performance anode material for lithium ion batteries. J Mater Chem A 2:1836718374

19. Nithya C, Gopukumar S (2013) Reduced graphite oxide/nano Sn: a superior composite anode material for rechargeable lithium-ion batteries. ChemSusChem 6:898-904

20. Boukamp BA, Lesh GC, Huggins RA (1981) All-solid lithium electrodes with mixed conductor matrix. J Electrochem Soc 128: $725-729$

21. Takamura T, Endo K, Fu L, Wu Y, Lee K, Matsumoto T (2007) Identification of nano-sized holes by TEM in the graphene layer of graphite and the high rate discharge capability of Li-ion battery anodes. Electrochim Acta 53:1055-1061

22. Novoselov KS, Jiang D, Schedin F, Booth TJ, Khotkevich VV, Morozov SV, Geim AK (2005) Two-dimensional atomic crystals. Proc Natl Acad Sci U S A 102:10451-10453

23. Wan D, Yang C, Lin T, Tang Y, Zhou M, Zhong Y, Huang F, Lin J (2012) Low-temperature aluminum reduction of graphene oxide, electrical properties, surface wettability, and energy storage applications. ACS Nano 6:9068-9078

24. Stankovich S, Dikin DA, Piner RD, Kohlhaas KA, Kleinhammes A, Jia Y, Wu Y, Nguyen ST, Ruoff RS (2007) Synthesis of graphene-based nanopapers via chemical reduction of exfoliated graphite oxide. Carbon 45:1558-1565

25. Wang G, Yang J, Park J, Gou X, Wang B, Liu H (2008) Facile synthesis and characterization of graphene nanopapers. J Phys Chem C 112:8192-8195

26. Si Y, Samulski ET (2008) Synthesis of water soluble graphene. Nano Lett 8:1679-1682

27. Fan ZJ, Wang K, Yan J, Wei T, Zhi LJ, Feng J, Ren YM, Song LP, Wei F (2011) Facile synthesis of graphene nanopapers via Fe reduction of exfoliated graphite oxide. ACS Nano 5:191-198

28. Fan ZJ, Wang K, Wei T, Yan J, Song LP, Shao B (2010) An environmentally friendly and efficient route for the reduction of graphene oxide by aluminum powder. Carbon 48:1670-1692

29. Zhu YW, Stoller MD, Cai WW, Velamakanni A, Piner RD, Chen D (2010) Exfoliation of graphite oxide in propylene carbonate and thermal reduction of the resulting graphene oxide platelets. ACS Nano 4:1227-1233

30. Compton OC, Jain B, Dikin DA, Abouimrane A, Amine K, Nguyen ST (2011) Chemically active reduced graphene oxide with tunable C/O ratios. ACS Nano 5:4380-4391

31. Wen ZH, Cui SM, Kim HJ, Mao S, Yu KH, Lu GH, Pu HH, Mao O, Chen JH (2012) Binding Sn-based nanoparticles on graphene as the anode of rechargeable lithium ion batteries. J Mater Chem 22: 3300-3306

32. Yue WB, Yang S, Ren Y, Yang XJ (2013) In situ growth of Sn, SnO on graphene nanosheets and their application as anode materials for lithium-ion batteries. Electrochim Acta 92:412-420

33. Sathish M, Mitani S, Tomai T (2012) Nanocrystalline tin compounds/graphene nanocomposite electrodes as anode for lithium-ion battery. J Solid State Chem 16:1767-1774

34. Chen SQ, Wang Y, Ahn H (2012) Microwave hydrothermal synthesis of high performance tin-graphene nanocomposites for lithium ion batteries. J Power Sources 216:22-27

35. Liang SZ, Zhu XF, Lian PC (2011) Superior cycle performance of $\mathrm{Sn@C/graphene} \mathrm{nanocomposite} \mathrm{as} \mathrm{an} \mathrm{anode} \mathrm{material} \mathrm{for} \mathrm{lithium-}$ ion batteries. J Solid State Chem 184:1400-1404

36. Wang DN, Li XF, Yang JL, Wang JJ, Geng DS, Li RY, Cai M, Sham TK, Sun XL (2013) Hierarchical nanostructured core-shell Sn@C nanoparticles embedded in graphene nanosheets: spectroscopic view and their application in lithium ion batteries. Phys Chem Chem Phys 15:3535-3542

37. Qin J, He C, Zhao N, Wang Z, Shi C, Liu E-Z, Li J (2014) Graphene networks anchored with Sn@graphene as lithium ion battery anode. ACS Nano 8:1728-1738

38. Zou Y, Wang Y (2011) Sn@CNT nanostructures rooted in graphene with high and fast Li-storage capacities. ACS Nano 5:8108-8114

39. Luo B, Wang B, Li XL, Jia YY, Liang MH, Zhi LJ (2012) Graphene-confined Sn nanosheets with enhanced lithium storage capability. Adv Mater 24:3538-3543

40. Luo B, Wang B, Liang MH, Ning J, Li XL, Zhi LJ (2012) Reduced graphene oxide-mediated growth of uniform tin-core/carbon-sheath coaxial nanocables with enhanced lithium ion storage properties. Adv Mater 24:1405-1409 
41. Ji LW, Tan ZK, Kuykendall T, An EJ, Fu YB, Battaglia V, Zhang YG (2011) Multilayer nanoassembly of Sn-nanopillar arrays sandwiched between graphene layers for high capacity lithium storage. Energy Environ Sci 4:3611-3616

42. Wang GX, Wang B, Wang XH, Park J, Dou SX, Ahn H, Kim K (2009) Sn/graphene nanocomposite with 3D architecture for enhanced reversible lithium storage in lithium ion batteries. J Mater Chem 19:8378-8384

43. Li YY, Li ZS, Shen PK (2013) Simultaneous formation of ultrahigh surface area and three-dimensional hierarchical porous graphenelike networks for fast and highly stable supercapacitors. Adv Mater 25:2474-2480

44. Zhang WM, Hu JS, Guo YG, Zheng SF, Zhong LS, Song WG, Wan LJ (2008) Tin-nanoparticles encapsulated in elastic hollow carbon spheres for high-performance anode material in lithium-ion batteries. Adv Mater 20:1160-1165

45. Xu YH, Liu Q, Zhu YJ, Liu YH, Langrock A, Zachariah MR, Wang CS (2013) Uniform nano-Sn/C composite anodes for lithium ion batteries. Nano Lett 13:470-474

46. Su YZ, Li S, Wu DQ, Zhang F, Liang HW, Gao PF, Cheng C, Feng XL (2012) Two-dimensional carbon-coated graphene/ metal oxide hybrids for enhanced lithium storage. ACS Nano 6:8349-8356

47. Zhong C, Wang JZ, Chen ZX, Liu HK (2011) $\mathrm{SnO}_{2}$-graphene composite synthesized via an ultrafast and environmentally friendly microwave autoclave method and its use as a superior anode for lithium-ion batteries. J Phys Chem C 115:25115-25120

48. Zhu X, Zhu Y, Murali S, Stoller MD, Ruoff RS (2011) Reduced graphene oxide/tin oxide composite as an enhanced anode material for lithium ion batteries prepared by homogenous coprecipitation. J Power Sources 196:6473-6477

49. Harrison KL, Manthiram A (2011) Microwave-assisted solvothermal synthesis and characterization of metastable $\mathrm{LiFe}_{1-\mathrm{x}}(\mathrm{VO})_{\mathrm{x}} \mathrm{PO}_{4}$ cathodes. Inorg Chem 50:3613-3620

50. Yoon S, Manthiram A (2011) Microwave-hydrothermal synthesis of $\mathrm{W}_{0.4} \mathrm{Mo}_{0.6} \mathrm{O}_{3}$ and carbon-decorated $\mathrm{WO}_{\mathrm{x}}-\mathrm{MoO}_{2}$ nanorod anodes for lithium ion batteries. J Mater Chem 21:4082-4085
51. Birrozzi A, Raccichini R, Nobili F, Marinaro M, Tossici R, Marassi $\mathrm{R}$ (2014) High-stability graphene nano sheets $/ \mathrm{SnO}_{2}$ composite anode for lithium ion batteries. Electrochim Acta 137:228-234

52. Fukuda K, Kikuya K, Isono K, Yoshio M (1997) Foliated natural graphite as the anode material for rechargeable lithium-ion cells. J Power Sources 69:165-168

53. Maroni F, Raccichini R, Birrozzi A, Carbonari G, Tossici R, Croce F, Marassi R, Nobili F (2014) Graphene/silicon nanocomposite anode with enhanced electrochemical stability for lithium-ion battery applications. J Power Sources 269:873-882

54. Cote LJ, Cruz-Silva R, Huang J (2009) Flash reduction and patterning of graphite oxide and its polymer composite. J Am Chem Soc 131:11027-11032

55. Reza-Azimi H, Rezaei M, Majidi F (2014) The non-isothermal degradation kinetics of St-MMA copolymers. Polym Degrad Stab 99:240-248

56. Meschini I, Nobili F, Mancini M, Marassi R, Tossici R, Savoini A, Focarete ML, Croce F (2013) High-performance Sn@carbon nanocomposite anode for lithium batteries. J Power Sources 226:241248

57. Nobili F, Meschini I, Mancini M, Tossici R, Marassi R, Croce F (2013) High-performance Sn@carbon nanocomposite anode for lithium-ion batteries: lithium storage processes characterization and low-temperature behavior. Electrochim Acta 107:85-92

58. Kaskhedikar NA, Maier J (2009) Lithium storage ion carbon nanostructures. Adv Mater 21:2664-2680

59. Zheng T, McKinnon WR, Dahn JR (1996) Hysteresis during lithium insertion in hydrogen-containing carbons. J Electrochem Soc $143: 2137-2145$

60. Botas C, Carriazo D, Singh G, Rojo T (2015) $\mathrm{Sn}-$ and $\mathrm{SnO}_{2-}$ graphene flexible foams suitable as binder-free anodes for lithium ion batteries. J Mater Chem A 3:13402-13410

61. Peukert W (1897) Über die Abhänigkeit der Kapazität von der Entladestromstärke bei Bleiakkumulatoren. Elektrotechnisch Z 27:287-288

62. Omar N, Van den Bossche P, Coosemans T, Van Mierlo J (2013) Peukert revisited-critical appraisal and need for modification for lithium-ion batteries. Energies 6:5625-5641 